\title{
Synthesis of Core-shell Star Poly(methyl methacrylate) with Benzene Arborol Core by Atom Transfer Radical Polymerization
}

\author{
By Huaihong ZHANG, ${ }^{1, *}$ Ziqun HUANG, ${ }^{2}$ and Qiang ZHANG ${ }^{2}$
}

Core-shell type star poly(methyl methacrylate) (PMMA) with benzene arborol core and linear PMMA shell having controlled chain lengths and numbers average molecular weights were synthesized by atom transfer radical polymerization (ATRP) of methyl methacrylate (MMA) in the presence of multifunctional benzene arborol macroinitiator. From the point of structure of polymer, it is very important to design the monomer and polymerization for a polymer with unique structure. The obtained copolymers were characterized by GPC, ${ }^{1} \mathrm{H}$ NMR, FT-IR, TGA and DSC. The molecular weight distributions of these copolymers were narrow $\left(1.13 \leq M_{\mathrm{w}} / M_{\mathrm{n}} \leq 1.21\right)$. The molecular weights of core-shell star copolymer could be controlled by the molar ratios of MMA to macroinitiator for a given polymerization time. The results show that dendrimers could be used as cores to synthesize dendritic star and star-block polymers by ATRP. In addition, the polymers can self-assemble into the spherical nanoparticles in a selective solvent $\left(\mathrm{DMSO} / \mathrm{H}_{2} \mathrm{O}\right)$.

KEY WORDS: Core-shell / Atom Transfer Radical Polymerization / Macroinitiator / Synthesis /

More and more attention has been attracted toward starshaped homopolymers and star-block copolymers due to their branched structures and unique physicochemical properties different from those of their linear polymeric counterparts. ${ }^{1-6}$ Generally, two methods are employed to prepare these polymers. One is the so-called "core first" method in which a multifunctional initiator is used to initiate the polymerization of monomer to form multiarm star polymers. ${ }^{1,2}$ The other is the so-called "arm first" strategy in which linear living polymer is synthesized initially, following by coupling reaction with a multifunctional coupling agent. ${ }^{6}$ So far, the "core first" method has proven very efficient to prepare well-defined star polymers, including dendritic star polymers. Dendrimers are monodisperse molecules with well-defined and perfectly branched structure, and many terminal groups are located on the surface of molecule, which can provide unique properties such as high surface reactivity. ${ }^{7-17}$ Therefore, dendrimers could be used as cores to synthesize dendritic star and star-block polymers.

As a robust and versatile polymerization approach, atom transfer radical polymerization (ATRP) has been attracting increasing interest recently, since it furnishes control over the resulting polymers. ${ }^{18-22}$ This method offers a facile way to form well-defined and predictable multicomponent polymer structures. Up to now, ATRP has been successfully applied to the synthesis of well-defined macromolecular architecture such as comb, gradient, star, and dendritic macromolecules. ${ }^{23-25}$

A closer look of the ATRP system and the core-shell star structures gives one an idea of making star block copolymers using alternative approach via dendritic structure, i.e., it seems possible to make a nearly symmetric core-shell star structure by polymerization of acrylate type monomer from the initiation of dendritic initiator via ATRP. Use of dendritic polymers as replacement of corresponding multifunctional polymer in the synthesis of symmetric core-shell like structures, however, has rarely been reported.

Here our laboratory demonstrates the application of the ATRP method to synthesize the core-shell star copolymers, in which the star arms part length can be controlled by molar ratio of monomer to macroinitiator. The functional core-shell star copolymers have been synthesized as an illustration of the importance of controlling polymer structures in the design of new materials.

\section{EXPERIMENTAL}

\section{Materials}

Methyl methacrylate (MMA) was purchased from Chengdu Kelong Chemical Reagent Factory (Chengdu, China) and distilled under reduced pressure over calcium hydride prior to use. $\mathrm{CuBr}$ from Shanghai Chemical Reagent Corporation (Shanghai, China) was purified by stirring in acetic acid and washing with ethanol and then dried in vacuum. 2,2'-Bipyridyl (bipy), 2-bromopropionyl bromide, aluminum oxide (neutral) were used as received from Aldrich (USA). Demethylformamide (DMF, Analysis grade), triethylamine (TEA, Analysis grade) and chloroform $\left(\mathrm{CHCl}_{3}\right.$, Analysis grade) were purchased from Shanghai Chemical Reagent Corporation (Shanghai, China) and were distilled from $\mathrm{CaH}_{2}$ under reduced pressure before used. Linear Poly(methyl methacrylate) $\left(M_{\mathrm{n}}=\right.$ 83000, $M_{\mathrm{w}} / M_{\mathrm{n}}=1.19$ ) was donated from Anhui HuaRun Materials Company. Benzene-[9] $]^{3}$-arborol (BA, dendritic core) was prepared by the literature method. ${ }^{26}$

\section{Synthesis of Dendritic Initiators (BA-Br)}

A typical example is given below. Benzene [9] $]^{3}$-arborol $(5.94 \mathrm{~g}, 0.108 \mathrm{~mol}$ of $\mathrm{OH}$ group) was dissolved in anhydrous

\footnotetext{
${ }^{1}$ College of Chemistry and Chemical Engineering, Southeast University, JiangSu, Nanjing 210096, China

${ }^{2}$ Department of Chemistry and Life Science, Wanxi College, AnHui, Liuan 237001, China

*To whom correspondence should be addressed (Tel: +86-0-1377-657-1947, E-mail: zhuaih99@yahoo.com.cn).
} 
DMF $(70 \mathrm{~mL})$ under stirring. To this solution was added TEA $(10.96 \mathrm{~g}, 0.108 \mathrm{~mol})$ under nitrogen at room temperature. The mixture was stirred and cooled to $0{ }^{\circ} \mathrm{C}$ with ice bath. Then 2bromopropionyl bromide $(32.4 \mathrm{~g}, 0.15 \mathrm{~mol})$ in anhydrous DMF $(30 \mathrm{~mL})$ was added dropwise to the mixture within $40 \mathrm{~min}$. The reaction mixture was stirred for $30 \mathrm{~h}$ at room temperature. Then the solid was separated from the mixture by filtration, washed with a large amount of cold methanol and dried under vacuum to constant weight. ${ }^{1} \mathrm{H} \mathrm{NMR}\left(\mathrm{CDCl}_{3}, \delta, \mathrm{ppm}\right)$ : $1.89-1.91$ $\left(-\mathrm{CH}_{3}\right), 4.40$ (-CHBr), $3.94\left(-\mathrm{COOCH}_{2}\right), 4.68$ (-CONH), 3.71$3.76\left(-\mathrm{ArCH}_{2}\right), 6.91-7.09$ (-ArH).

\section{Synthesis of Core-shell Star PMMA}

In a general procedure, an oven-dried Schlenk tubes was charged with bipy $(93.60 \mathrm{mg}, 0.60 \mathrm{mmol}), \mathrm{CuBr}$ (43.10 mg, $0.30 \mathrm{mmol})$, dendritic $\mathrm{BA}-\mathrm{Br}$ initiator $(1.54 \mathrm{~g}$, containing $0.30 \mathrm{mmol}$ of $\mathrm{C}-\mathrm{Br}), \mathrm{CHCl}_{3}(20 \mathrm{~mL})$ and a magnetic stirring bar. The tube was degassed three cycles by pulling a vacuum and back-filling with nitrogen gas. Then, deoxygenated MMA $(3.00 \mathrm{~g}, 0.03 \mathrm{~mol}$ was added via syringe. The reaction was performed at $80^{\circ} \mathrm{C}$ for $12 \mathrm{~h}$. The crude product was dissolved in $\mathrm{CHCl}_{3}$ and passed through a neutral aluminum oxide column to remove the copper catalysts. The product was obtained by precipitation into cold methanol and dried under vacuum to constant weight. Samples were taken periodically via syringe to monitor the conversion and molecular weight. The monomer conversion was determined gravimetrically. ${ }^{1} \mathrm{H} \mathrm{NMR}\left(\mathrm{CDCl}_{3}\right.$, $\delta$, ppm): 0.84 and 1.02 (-CH $\mathrm{CH}_{3}$, in PMMA), $1.71-1.94\left(-\mathrm{CH}_{2}\right.$, in PMMA), 3.80 (- $\mathrm{COOCH}_{3}$, in PMMA), $4.49\left(-\mathrm{OCOCH}_{2}\right.$, in $\mathrm{BA}-\mathrm{Br}), 2.11\left(-\mathrm{CH}_{3}\right.$, in $\left.\mathrm{BA}-\mathrm{Br}\right)$.

\section{Characterization}

The monomer conversion was determined gravimetrically. The number-average molecular weight $\left(M_{\mathrm{n}}\right)$ and polydispersities $\left(M_{\mathrm{w}} / M_{\mathrm{n}}\right)$ of the obtained polymers were measured at $35^{\circ} \mathrm{C}$ by gel permeation chromatography (GPC) on a waters 2410 instrument using $\mathrm{THF}$ as the solvent $(1.0 \mathrm{~mL} / \mathrm{min})$, calibration with polystyrene standards, and Waters Millenium 32 as the dataprocessing software. ${ }^{1} \mathrm{H}$ NMR spectra were taken at $25^{\circ} \mathrm{C}$ on a Brucker $\mathrm{ARX} 400(400 \mathrm{MHz})$ spectrometer in $\mathrm{CDCl}_{3}$ using tetramethysilane as internal reference. The IR spectra were recorded on Perkin-Elmer Spectrum 2000 Fourier transform infrared spectrometer by using $\mathrm{KBr}$ pellets. Thermal gravimetry analysis (TGA) was carried out on SDTQ-600 thermalgravimetric analyzer under $\mathrm{N}_{2}$ atmosphere in the temperature range of $50-500{ }^{\circ} \mathrm{C}$, at a heating rate of $10^{\circ} \mathrm{C}$ / min. Differential scanning calorimetry (DSC) was performed on a PE-7 thermal analysis system. under $\mathrm{N}_{2}$ atmosphere with a temperature range of $50-180^{\circ} \mathrm{C}$, at a heating rate of $10^{\circ} \mathrm{C} / \mathrm{min}$. Transmission electron micrographs were obtained on a JEOL model 1200EX instrument operated at an accelerating voltage at $160 \mathrm{kV}$.

\section{RESULTS AND DISCUSSION}

Macroinitiator and the synthetic strategy followed for the
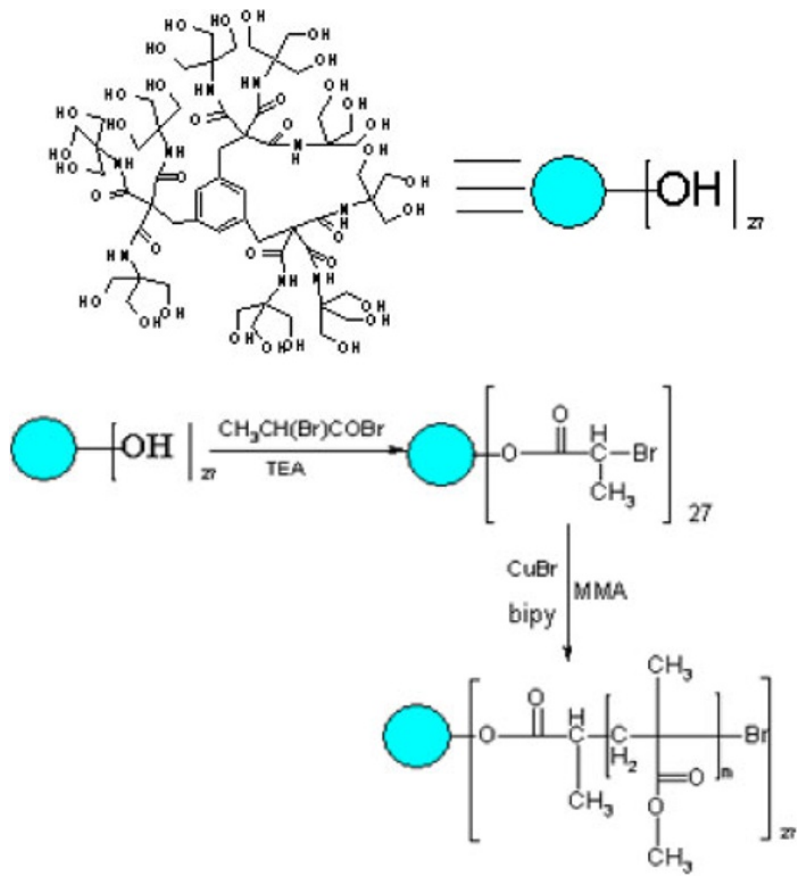

Scheme 1. Synthesis of core-shell star copolymer by atom transfer radical polymerization.

preparation of well-defined core-shelled star PMMA via ATRP route are depicted in Scheme 1.

\section{Polymerization Analysis}

Compared with other living radical polymerization methods, ATRP offers high degrees of conversion and tolerance for a variety of functional groups, while still allowing for control of the molecular weight and narrow molecular weight distributions. The polymerizations of MMA are carried out in a sealed tube by using $\mathrm{CuBr}$ as catalyst and bipy as ligand in the presence of dendritic initiator (BA-Br) at certain temperature, the results are shown in Table I. It is found that MMA with dendritic macroinitiator can be polymerized successfully by ATRP to give core-shell star copolymers with relatively narrow polydispersity $\left(1.13 \leqslant M_{\mathrm{w}} / M_{\mathrm{n}} \leqslant 1.21\right)$. In the polymerization of MMA with $\mathrm{BA}-\mathrm{Br}$ at $80^{\circ} \mathrm{C}$ shown in Table I, the $\mathrm{CuBr} /$ bipy seems to be a suitable catalyst system and relatively high conversion and molecular weight is obtained.

Table I. Results for ATRP of MMA with dendritic initiator BA-Br

\begin{tabular}{ccrrrcc}
\hline Sample & Time (h) & $M_{\mathrm{n}, \mathrm{th}}{ }^{\mathrm{a}}$ & $M_{\mathrm{n}, \mathrm{NMR}}{ }^{\mathrm{b}}$ & $M_{\mathrm{n}, \mathrm{GPC}^{\mathrm{c}}}$ & $M_{\mathrm{w}} / M_{\mathrm{n}}{ }^{\mathrm{c}}$ & Conversion $^{\mathrm{d}}(\%)$ \\
\hline 1 & 2 & 46170 & 47800 & 43280 & 1.14 & 15.2 \\
2 & 3 & 81000 & 83250 & 78630 & 1.13 & 28.1 \\
3 & 4 & 111510 & 134780 & 104980 & 1.16 & 39.4 \\
4 & 5 & 143910 & 170870 & 140570 & 1.15 & 51.4 \\
5 & 6 & 155250 & 181500 & 152150 & 1.21 & 55.6 \\
\hline
\end{tabular}

${ }^{\mathrm{a}} M_{\mathrm{n}, \mathrm{th}}=M_{\text {monomer }} \times([$ monomer $] /[\mathrm{C}-\mathrm{Br}]) \times 27 \times$ conversion $(\%)+M_{\text {macroinitiator }}$ [monomer] $/[\mathrm{C}-\mathrm{Br}]=100$. ${ }^{\mathrm{b}}$ Determined by ${ }^{1} \mathrm{H}$ NMR spectroscopy of shellcore star diblock copolymer. ${ }^{\mathrm{C} D e t e r m i n e d ~ b y ~ G P C}$ analysis with polystyrene standards. THF used as eluent. ${ }^{d}$ Calculated from: $\left[W_{\mathrm{p}} /\left(W_{\mathrm{i}}+W_{\mathrm{m}}\right)\right] \mathbf{x}$ $100 \%$, where $W_{\mathrm{p}}, W_{\mathrm{i}}$, and $W_{\mathrm{m}}$ were the weight of the diblock copolymer produced and the initial weights of the related macroinitiator and monomer, respectively. 


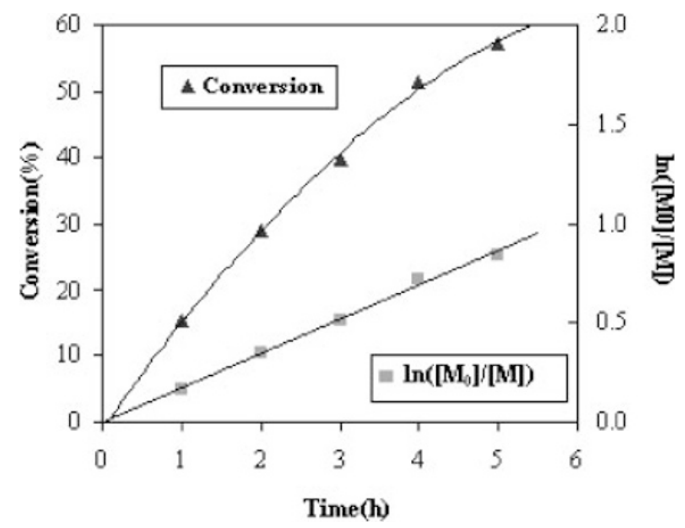

Figure 1. Kinetic plot for ATRP of MMA with dendritic $B A-B r$ initiator. [MMA]:[C-Br]:[CuBr]:[bipy] = 100:1:1:2 in $\mathrm{CHCl}_{3}$ at $80^{\circ} \mathrm{C}$.

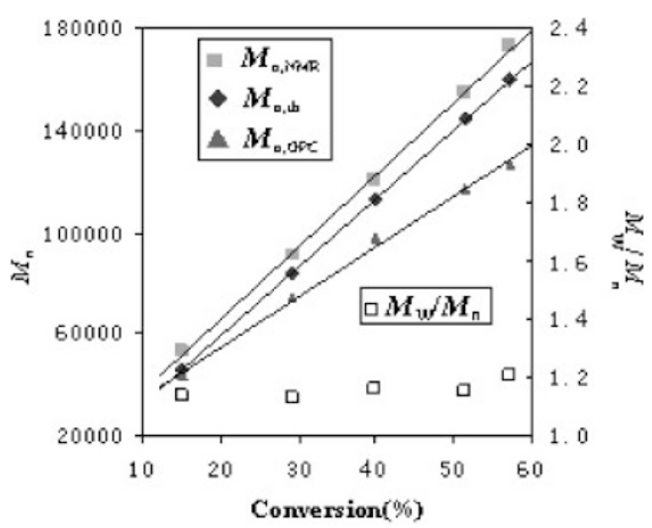

Figure 2. Evolution of $M_{\mathrm{n}}$ and $M_{\mathrm{w}} / M_{\mathrm{n}}$ of core-shell star polymer PMMA with conversion for ATRP of MMA. Polymerization conditions see Figure 1.

In the course of polymerization, the kinetic plot of the coreshell star block PMMA copolymer formation is shown in Figure 1. The conversion of MMA reached $55.6 \%$ in $6 \mathrm{~h}$ in $\mathrm{CHCl}_{3}$. The plot of $\ln \left(\left[\mathrm{M}_{0}\right] /[\mathrm{M}]\right)$ against polymerization time seemed linear and crossed the zero point. This result demonstrated that the first-order kinetics could be maintained until relative high conversion, suggesting the concentration of active species remained constant throughout the course of polymerization of PMMA. It could be seen from Figure 2 that $M_{\mathrm{n}, \mathrm{NMR}}$ values were close to $M_{\mathrm{n}, \mathrm{th}}$, increased linearly with conversion, indicating that the molecular weight of the copolymer could be manipulated by the control of monomer conversion. Moreover, the molecular weight distributions of the copolymers were narrow $\left(M_{\mathrm{w}} / M_{\mathrm{n}} \leqslant 1.21\right)$. Obviously, the dendritic BA-Br could be used as an efficient multifunction macroinitiator for living polymerization of MMA to form coreshell star polymer PMMA.

The GPC trace of the core-shell star copolymer is shown in Figure 3. It could be seen that the trace was monomodal and the GPC peak of the core-shell star polymer shifted toward higher molecular weight with increasing the conversion of monomer in the reaction procedure. Furthermore, according to the data given in Table I, the molecular weights determined by

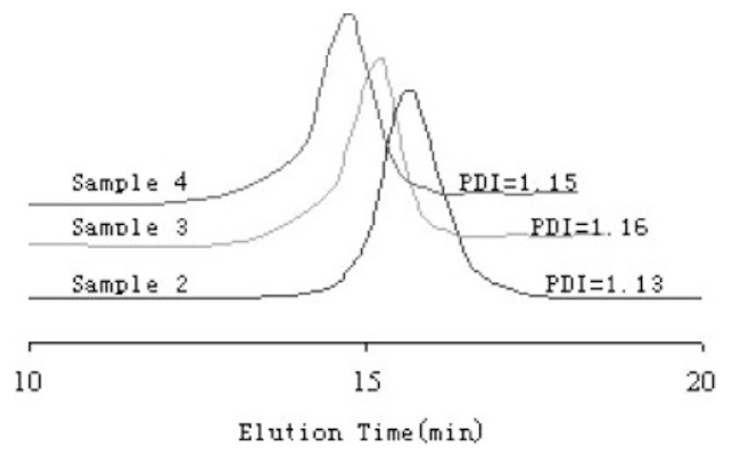

Figure 3. GPC traces of dendritic star PMMA with variation conversion.

GPC $\left(M_{\mathrm{n}, \mathrm{GPC}}\right)$ were slightly lower than those determined by ${ }^{1} \mathrm{H}$ NMR $\left(M_{\mathrm{n}, \mathrm{NMR}}\right)$ and theoretic values $\left(M_{\mathrm{n}, \mathrm{th}}\right)$ and the value of $M_{\mathrm{n}, \mathrm{NMR}}$ is close to $M_{\mathrm{n}, \mathrm{th}}$. This phenomenon can be ascribed to the structure of resultant polymers because of their different hydrodynamic volumes compared with linear polymer having the same molecular weight. ${ }^{27}$

\section{Characterization and Thermal Properties}

The characterization of core-shell star PMMA was investigated with FT-IR and ${ }^{1} \mathrm{H}$ NMR. As shown in Figure 4, the characteristic absorption peak of the multifounction macroinitiator (BA-Br) about at $3500 \mathrm{~cm}^{-1}$, that is contributed to the $\mathrm{N}-\mathrm{H}$ stretching vibration. After the esterification of benzne arborol with 2-bromopropionyl bromide, the $\mathrm{C}=\mathrm{O}$ absorption band became wide obviously and split into two peaks. The peak at $1750 \mathrm{~cm}^{-1}$ corresponded to the $\mathrm{C}=\mathrm{O}$ absorption of 2-bromopropionate units, while the peak at $1730 \mathrm{~cm}^{-1}$ was assigned to the $\mathrm{C}=\mathrm{O}$ absorption of the BA units. It is known that the tertiary bromoester-groups are effective initiator for ATRP of methylacrylate and styrene derivatives. ${ }^{25}$ In the case of core-shell star PMMA, these characteristic absorption peaks of the PMMA were apparent. However, these characteristic absorption peaks of the core units are hard to be observed for enwrapping a thick of PMMA outside of benzene arborol core. The similar phenomena are also observed in the ${ }^{1} \mathrm{H}$ NMR (Figure 5).

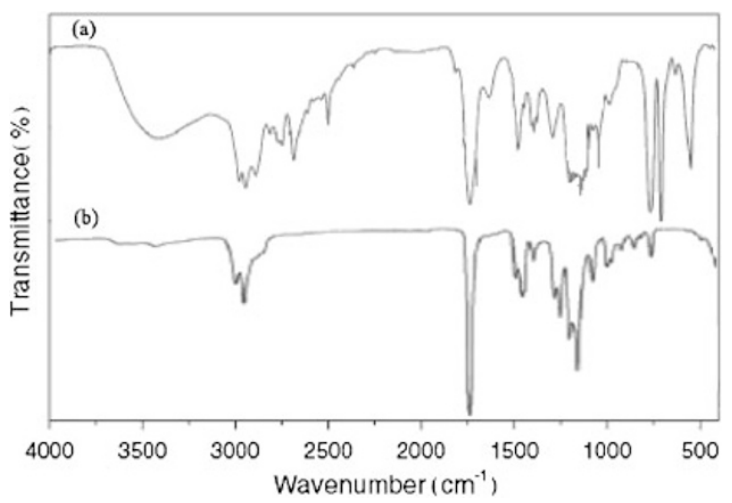

Figure 4. IR spectra of $\mathrm{BA}-\mathrm{Br}$ macroinitiator (a), and core-shell star PMMA (b). 

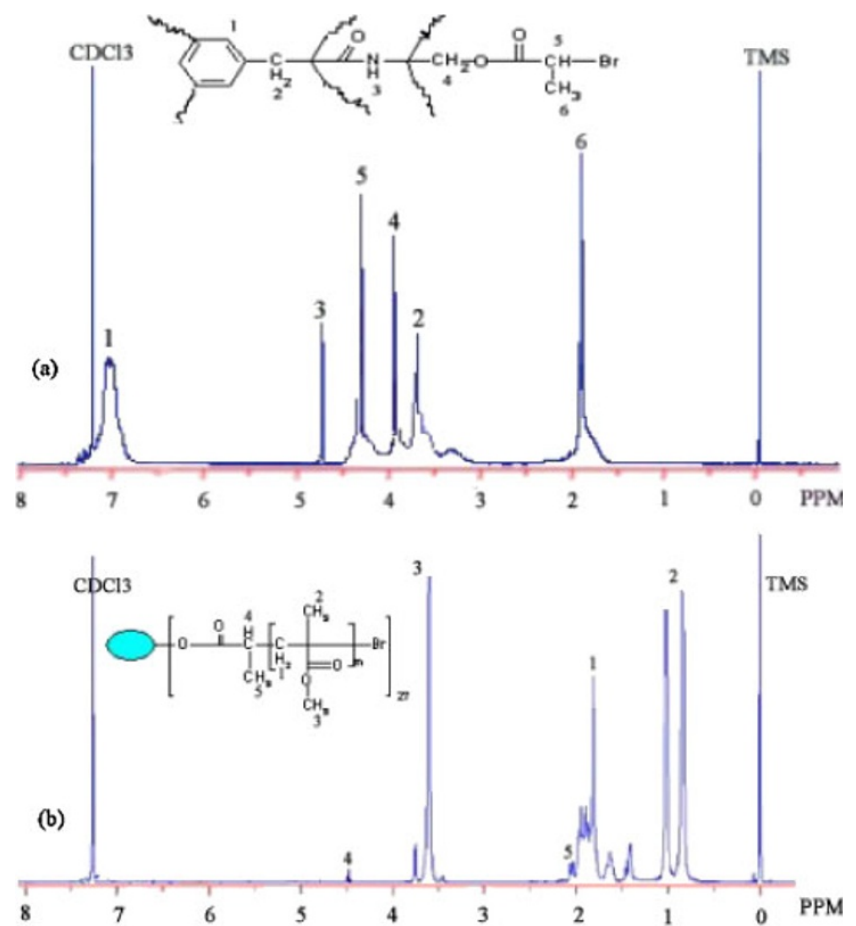

Figure 5. ${ }^{1} \mathrm{H}$ NMR spectra of $\mathrm{BA}-\mathrm{Br}$ macroinitiator (a), and core-shell star PMMA (b).

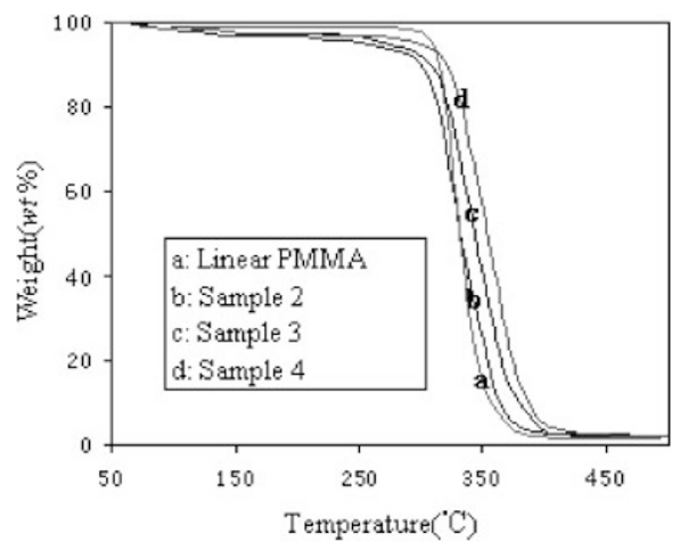

Figure 6. TGA curves of linear PMMA and core-shell star PMMA (sample 2, $3,4)$.

Thermal degradation studies with TGA. TGA is a technique used to accurately track the in situ weight changes of a sample during a heating process, thereby providing information on thermal degradation. Figure 6 shows the TGA curves of four polymers, linear PMMA and core-shell star PMMA (sample 2, $3,4)$, respectively. From the Figure 6, it is evident that the thermal degradation temperature region of the core-shell star samples at around $340^{\circ} \mathrm{C}$, which close to linear PMMA. This is mainly due to dendritic core segments have little effect on the resultant polymers compared with PMMA homopolymer for the relatively low content in the polymers.

To investigate the relationship between the glass transition temperature $\left(T_{\mathrm{g}}\right)$ of the core-shell star copolymer and the

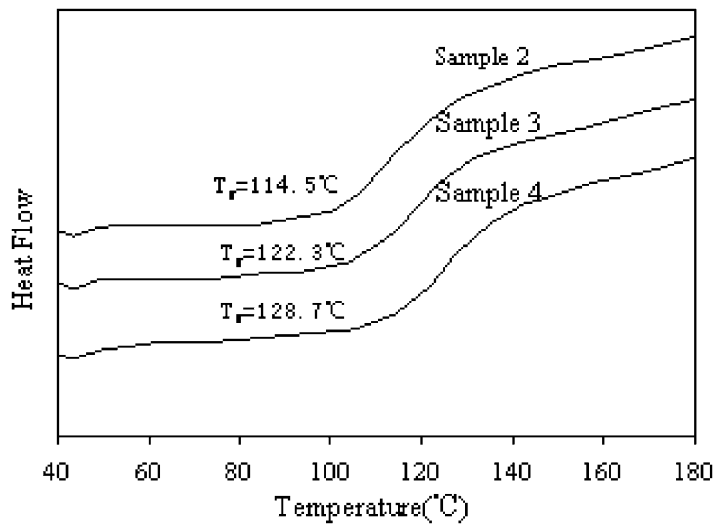

Figure 7. DSC curves of the core-shell star PMMA.

number average molecular weight of copolymer, the DSC curves of the core-shell star copolymer were made. The number average molecular weight of the core-shell star copolymer was controlled by different conversion of the monomer. From Figure 7, $T_{\mathrm{g}}$ of the core-shell star copolymers increase gradually with the molecular weight of copolymers. Meanwhile, the only one glass transition temperature $\left(T_{\mathrm{g}}\right)$ observed throughout the whole scan range from 50 to $180^{\circ} \mathrm{C}$. It was further confirmed that the core-shell star PMMA with benzene arborol core was synthesized.

\section{Self-assembly Properties of Core-shell Star PMMA Copoly- mer}

Different morphologies of self-assembly systems are basically related to the chemical composition of the copolymer and to the relative volume ratio of the two blocks. Among the possible morphologies, spherical micelles are of special interest because they can lead to encapsulating active molecules such as DNA, enzymes, or drugs.

Figure 8 shows micrographs obtained from a solution of the core-shell star poly(methyl methacrylate) in $\mathrm{DMSO} / \mathrm{H}_{2} \mathrm{O}$ $(1: 1, \mathrm{v} / \mathrm{v})$ with concentration at $5 \mathrm{mg} / \mathrm{mL}$. From Figure 8 , the diameter of the micro-sphere increases slowly with the number-average molecular weight of the core-shell star PMMA: diameter of the sample 2 around $150 \mathrm{~nm}$, sample 3 around $250 \mathrm{~nm}$ and sample 4 around $300 \mathrm{~nm}$ respectively. It is well known the different morphologies of self-assembly systems are basically related to the chemical composition of the copolymers. The core-shell star PMMA copolymers consist of two segments: a benzene arborol core and many PMMA arms. Because both of core and arms can be dissolved in DMSO, however, $\mathrm{H}_{2} \mathrm{O}$ is a poor solvent for PMMA. Therefore, it is assumed that the excess PMMA arms are encapsulated in the aggregates and benzene arborol cores are hidden in the center of the nanoparticles.

\section{CONCLUSIONS}

Novel core-shell star PMMA with different molecular weight were synthesized successfully by ATRP using benzene 


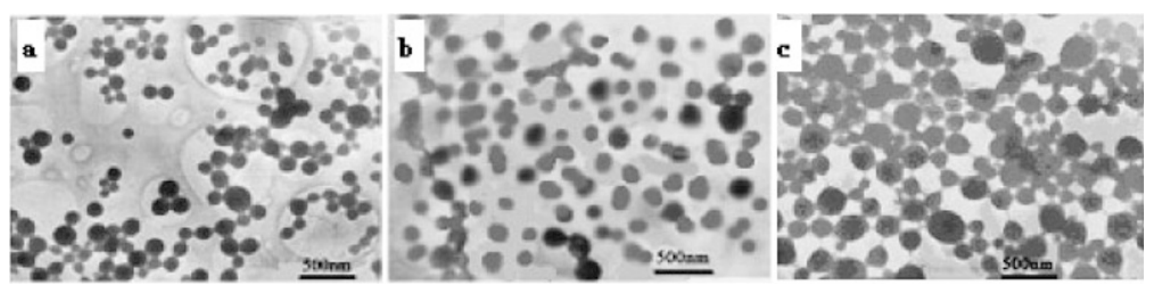

Figure 8. TEM photograph of core-shell star PMMA obtained in the mixed solvent $\left(\mathrm{DMSO} / \mathrm{H}_{2} \mathrm{O}=1: 1\right)(\mathrm{a})$ sample 2 , (b) sample 3 and (c) sample 4

arborol macroinitiator in the presence of $\mathrm{CuBr}$ and bipy as catalyst system. The structures of polymers were confirmed by FT-IR and ${ }^{1} \mathrm{H}$ NMR. GPC results showed that the resultant polymers had low polydispersity indices (PDI: 1.13-1.21). DSC analysis indicated that PMMA star polymers had only glass transition temperatures that varied with the molecular weight of the core-shell star PMMA. In addition, self-assembly nanoparticles of the core-shell star poly(methyl methacylate) could be found in the selected solvent (DMSO/ $\left.\mathrm{H}_{2} \mathrm{O}\right)$.

Received: January 5, 2008 Accepted: March 8, 2008 Published: April 23, 2008

\section{REFERENCES}

1. A. Heise, M. Trollsas, T. Magbitang, J. L. Hedrick, C. W. Frank, and R. D. Miller, Macromolecules, 34, 2798 (2001).

2. C. M. Dong, K. Y. Qiu, Z. W. Gu, and X. D. Feng, Macromolecules, 34, 4691 (2001).

3. Q. H. Hao, F. X. Li, Q. B. Li, Y. Li, L. Jia, and J. Yang, Biomacromolecules, 6, 2236 (2005).

4. F. Q. Zeng, H. Lee, M. Chidiac, and C. Allen, Biomacromolecules, 6 , 2140 (2005).

5. C. Cai, L. Wang, and C. M. Dong, J. Polym. Sci., Part A: Polym. Chem., 44, 2034 (2006).

6. N. Hadjichristidis, M. Pitsikalis, S. Pispas, and H. Iatrou, Chem. Rev., 101, 3747 (2001).

7. A. Cordova, A. Hult, K. Hult, H. Ihre, T. Iversen, and E. Malmstrom, J. Am. Chem. Soc., 120, 13521 (1998).

8. M. Trollsas and J. L. Hedrick, J. Am. Chem. Soc., 120, 4644 (1998).
9. A. F. Zhang, B. Zhang, E. Wachtersbach, M. Schmidt, and A. D. Schluter, Chem. Eur. J., 9, 6083 (2003).

10. A. F. Zhang, L. Okrasa, T. Pakula, and A. D. Schluter, J. Am. Chem. Soc., 126, 6658 (2004)

11. Y. L. Zhao, L. M. Chen, C. F. Chen, and F. Xi, Polymer, 46, 5808 (2005).

12. Y. L. Zhao, X. T. Shuai, C. F. Chen, and F. Xi, Macromolecules, 37, 8854 (2004).

13. R. C. Hedden and B. J. Bauer, Macromolecules, 36, 1829 (2003).

14. P. V. Persson, J. Casas, T. Iversen, and A. Cordova, Macromolecules, 39, 2819 (2006).

15. Q. Cai, Y. L. Zhao, J. Z. Bei, F. Xi, and S. G. Wang, Biomacromolecules, 4, 828 (2003).

16. C. Y. Hong, Y. Z. You, J. Liu, and C. Y. Pan, J. Polym. Sci., Part A: Polym. Chem., 43, 6379 (2005).

17. G. H. Jiang, L. Wang, T. Chen, and H. J. Yu, Polymer, 46, 81 (2005).

18. B. Jiang, Y. Yang, D. Jian, S. Fu, R. Zhu, J. Hao, and W. Wang, J. Appl. Polym. Sci., 83, 2114 (2002).

19. C. Celik, G. Hizal, and U. Tunca, J. Polym. Sci., Part A: Polym. Chem., 41, 2542 (2003).

20. K. Matyjaszewski, Polym. Int., 52, 1559 (2003).

21. M. Mennicken, R. Nagelsdiek, H. Keul, and H. Hocker, Macromol. Chem. Phys., 205, 143 (2004).

22. X. Zhu, Y. Gu, G. Chen, Z. Cheng, and J. Lu, J. Appl. Polym. Sci., 93, 1539 (2004).

23. J. Du and Y. Chen, J. Polym. Sci., Part A: Polym. Chem., 42, 2263 (2004).

24. P. Liu, L. Jin, J. Hu, and C. Wang, Polym. Int., 53, 136 (2004).

25. C. X. Cheng, R. P. Tang, Y. L. Zhao, and F. Xi, J. Appl. Polym. Sci., 91, 2733 (2004).

26. G. R. Newkome, Z. Q. Yao, G. R. Baker, V. K. Gupta, P. S. Russo, and M. J. Saunders, J. Am. Chem. Soc., 108, 849 (1986).

27. Y. L. Zhao, J. Jiang, C. F. Chen, and F. Xi, Polym. Int., 51, 1334 (2002). 